\title{
Laboreal
}

Volume $16 \mathrm{~N}^{\circ} 1 \mid 2020$

Quando o trabalho real é tabu

\section{Amianto : una contaminación sin fronteras, sin fin y con total impunidad*}

Amianto : uma contaminação sem fronteiras, sem fim e com total impunidade Amiante: une contamination sans frontières, sans fin, en toute impunité Asbestos: contamination without borders, without end and with total impunity

Annie Thébaud-Mony

Traductor. Fernanda Romero

(2) OpenEdition

Journals

Edición electrónica

URL: http://journals.openedition.org/laboreal/16206

DOI: $10.4000 /$ laboreal. 16206

ISSN: 1646-5237

Editor

Universidade do Porto

Referencia electrónica

Annie Thébaud-Mony, "Amianto : una contaminación sin fronteras, sin fin y con total impunidad* »,

Laboreal [En línea], Volume $16 \mathrm{~N}^{0} 1$ | 2020, Publicado el 01 julio 2020, consultado el 14 septiembre 2020. URL : http://journals.openedition.org/laboreal/16206

Este documento fue generado automáticamente el 14 septiembre 2020

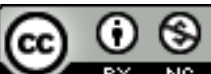

Laboreal está licenciado com uma Licença Creative Commons - Atribuição-NãoComercial 4.0 Internacional. 


\section{Amianto : una contaminación sin fronteras, sin fin y con total impunidad*}

Amianto : uma contaminação sem fronteiras, sem fim e com total impunidade Amiante: une contamination sans frontières, sans fin, en toute impunité Asbestos: contamination without borders, without end and with total impunity Annie Thébaud-Mony

Tradución : Fernanda Romero

\section{NOTA DEL EDITOR}

*Texto originalmente publicado como "Think piece" por la OIT (https://www.ilo.org/ global/topics/safety-and-health-at-work/events-training/events-meetings/world-dayfor-safety/33thinkpieces/WCMS_681629/lang--fr/index.htm).

Traducción : Fernanda Romero - fernandaromero.trad@gmail.com

1 Los hechos son conocidos desde finales del siglo XIX: independientemente de la variedad (anfíboles o crisotilo), el amianto es perjudicial para la salud y mata. ¡Pero no de inmediato! Con la excepción de los signos de fibrosis pulmonar, llamada "asbestosis" (o amiantosis), que pueden surgir tempranamente cuando hay una fuerte exposición a esta fibra mineral, los síntomas clínicos de los cánceres relacionados con el amianto aparecen más tarde, incluso algunas décadas después de la contaminación.

2 Aunque los industriales lo saben desde la década de 1930, fue necesario esperar por los trabajos de Irving Selikoff y de su equipo (Facultad de Medicina Monte Sinai de la Universidad de Nueva York), en el inicio de los años 1960, para que la dimensión de la epidemia de enfermedades relacionadas con el amianto fuera públicamente considerada una realidad. Las condiciones de trabajo en las fábricas de amianto en el 
inicio de los años 1970 eran catastróficas, como nos relata Josette Roudaire, una antigua obrera de la fábrica textil AMISOL en Clermont-Ferrand, Francia (Roudaire, 2018).

Fue también en esa época, mediados de la década de 1960, que el Brasil, un país que hasta entonces usaba muy poco amianto, empezó a explotar la mina más grande de Latinoamérica : Canabrava - Minaçu, en el Estado de Goiás. Y, en las décadas siguientes, es esta mina que convertirá a Brasil en el 3. productor mundial, en beneficio de dos empresas multinacionales europeas : Eternit (Suiza) y Saint Gobain (Francia).

4 A escala mundial, de los $\mathbf{1 8 2}$ millones de toneladas de amianto producido entre 1900 y 2004, el 80 \% lo fue después de 1960, es decir, cuando ya se conocían sus efectos nocivos para la salud y letales (McCulloch \& Tweedale, 2008).

5 En la actualidad, gracias a los esfuerzos de un frente común de ciudadanos, sindicatos y asociaciones presentes en todos los continentes, 55 países han prohibido el amianto. Pero la extracción y el consumo siguen alcanzando aproximadamente 2,03 millones de toneladas al año, según las cifras más recientes. Y, en febrero de 2020, Eternit-Brasil, que explotaba la mina de Canabrava - Minaçu y que había encerrado la empresa en 2019, anunció que retomaría "previsionalmente" su actividad [1], pero exclusivamente para exportar el remanente a países asiáticos $\left[{ }^{2}\right]$.

6 La dimensión de la epidemia de enfermedades relacionadas con el amianto es conocida, aunque bastante infravalorada debido a la impracticabilidad de realizar diagnósticos y a la baja fiabilidad de las fuentes estadísticas en muchos países.

7 Las más recientes estimaciones (de mortalidad) informan 255 mil muertes causadas por el amianto en todo el mundo, de las cuales 233 mil debidas a la exposición profesional (Furuya et al., 2018). Los casos episódicos no son registrados y las víctimas pocas veces son indemnizadas.

8 En el caso del amianto, hay tres grandes retos de salud pública y de justicia que figuran en la agenda nacional e internacional. El primero de todos es la necesidad de frenar la epidemia e impedir la aparición de nuevos casos. Se trata, por lo tanto, de conseguir una prohibición mundial y definitiva del amianto. Fue precisamente eso que la OIT ha aconsejado vivamente en su asamblea general en $\left.20066^{3}\right]$.

9 Una de las vías que podría apoyar dicho propósito es el Convenio de Róterdam sobre el Consentimiento Fundamentado Previo (procedimiento PIC: prior informed consent) aplicable a ciertos productos químicos peligrosos objeto de comercio internacional y que está en vigor desde $2004\left[{ }^{4}\right]$.

10 No obstante, dadas las enormes cantidades de amianto esparcidas por edificios públicos y privados, sistemas de suministro de agua y numerosas instalaciones industriales y comerciales, la prohibición del amianto no lo solucionaría todo. Se deberán adoptar medidas para que la eliminación del amianto existente, bien como de los residuos, se haga en condiciones que garanticen la protección de los trabajadores y de los residentes, evitando toda y cualquier nueva contaminación por el polvo de los trabajos de remoción y el deficiente almacenamiento de los residuos

11 El segundo reto es el de la justicia para os trabajadores afectados y respectivas familias. En el "Esquema para la elaboración de programas nacionales de eliminación de las enfermedades relacionadas con el asbesto"[5], la OIT y la OMS recomiendan crear "un registro central de todos los trabajadores expuestos al asbesto, incluso en el pasado". Aún según la OIT y la OMS, "debe organizarse una vigilancia médica para detectar tempranamente cualquier síntoma o trastorno originado por la exposición al asbesto". 
Si esto se hubiera hecho hace treinta años, el registro efectivo y oficial de las víctimas les habría permitido el derecho al reconocimiento y el derecho a indemnización en caso de una enfermedad profesional, complementado por otras formas de compensación (falta inexcusable del empleador, Fondo de indemnización para las víctimas de amianto). El seguimiento médico debería extenderse a los casos de exposición familiar y medioambiental, debiendo las víctimas en causa beneficiar de los mismos derechos en términos de indemnización.

Por fin, el último reto, pero no menos importante, es el del reconocimiento de la responsabilidad criminal de los empresarios industriales en esta catástrofe sanitaria mundial. De hecho, el 3 de marzo de 2002, el Consejo de Estado (o Tribunal Supremo Administrativo francés) reconoció la responsabilidad del Estado por "falla (u omisión) culposa" por no haber adoptado y aplicado medidas de prevención de los riesgos relacionados con la exposición de los trabajadores a los polvos de amianto. Todavía, y no obstante la acumulación de pruebas de las estrategias activas y deliberadas de disimulación de los efectos del amianto en la salud llevadas a cabo durante años por los directivos de las empresas multinacionales productoras y transformadoras (McCulloch \& Tweedale, 2008 ; David, 2008 ; Thébaud-Mony, 2014), estos han escapado hasta hoy de cualquier condena penal por los crímenes del trabajo de envenenamiento de miles y miles de víctimas $\left.{ }^{6}\right]\left[{ }^{7}\right]$.

13 Cien años después de la creación de la Organización Internacional del Trabajo, cuya finalidad es actuar en defensa de los derechos de los trabajadores, ¿será que la comunidad internacional puede dejar perdurar indefinidamente la impunidad de los agentes económicos responsables por catástrofes sanitarias como la del amianto, de las cuales los trabajadores son las principales víctimas, pero también las más invisibles?

\section{BIBLIOGRAFÍA}

David, M. (2008). Doubt is their product. How Industry's Assault on Science Treatens Your Health. New York : Oxford University Press.

Furuya, S., Chimed-Ochir, O., Ken Takahashii, K., David, A., \& Takala, J. (2018). Global Asbestos Disaster. International Journal of Environmental Research and Public Health, 15(5) : 1000. https://doi.org/10.3390/ijerph15051000

McCulloch, J., \& Tweedale, G. (2008). Defending the Indefensible. The Global Asbestos Industry and its Fight for Survival. New York : Oxford University Press.

Roudaire, J. (2018). Mémoires de luttes : quelques constats et réflexions. Communication au Colloque "Femmes - Cancer - Travail", Institut Syndical Européen (ETUI), Bruxelles, Belgique.

Thébaud-Mony, A. (2014). La science asservie. Santé publique : les collusions mortifères entre industriels et chercheurs. Paris : La Découverte. 


\section{NOTAS}

1. http://www.ibasecretariat.org/press_release_feb_14_2020.pdf

2. http://ibasecretariat.org/press-release-stop-brazilian-asbestos-exports-apr-21-2019.pdf

3. http://www.ilo.org/public/english/standards/relm/ilc/ilc95/pdf/pr-20.pdf

4. Efectivamente, después de 2006, con ocasión de las sesiones de la Conferencia de las Partes de este Convenio, la gran mayoría de los representantes y participantes defienden la inscripción del amianto variedad crisotilo en el Anexo III para que, como producto químico prohibido o rigurosamente restringido, sus exportaciones se sometan a dicho procedimiento PIC. Cabe precisar que en ese anexo ya están inscritas las variedades actinolita, antofilita, amosita, crocidolita y tremolita del amianto. Sin embargo, las expectativas de que dicha inscripción en el Anexo III fuese por fin decidida se desvanecieron en la reunión de las Partes de junio de 2019, una vez que una minoría de países productores impidió de nuevo el consenso necesario. Y, una vez más, el tema de la inscripción del amianto crisotilo como producto prohibido fue aplazada y, ahora, trasladado para la agenda de la próxima reunión de la Conferencia, prevista para el mes de julio de 2021 (http://www.pic.int/TheConvention/Overview/TextoftheConvention/tabid/1048/ language/en-US/Default.aspx).

5. https://www.who.int/occupational_health/publications/elim_asbestos_doc_fr.pdf?ua=1

6. https://blogs.mediapart.fr/annie-thebaud-mony/blog/211219/quand-lacondamnation-des-crimes-du-travail-pour-empoisonnement;

https://www.politis.fr/articles/2017/07/amiante-un-permis-de-tuer-pour-les-industriels-37273/ 7. De todos modos, refiéranse las demandas de la justicia italiana contra Eternit y su exadministrador y propietario, Stephan Schmidheiny: https://www.asso-henri-pezerat.org/ stephan-schmidheiny-eternit-va-etre-juge-pour-homicide-volontaire/; https://charliehebdo.fr/ 2020/02/ecologie/fabrice-nicolino-suisse-amiante-industrie-proces-schmidheiny-philanthropecriminel/

\section{AUTORES}

\section{ANNIE THÉBAUD-MONY}

INSERM/IRIS, Université Sorbonne Paris Nord, 74 rue marcel Cachin, 93017 - Bobigny-Cedex

annie.mony@gmail.com 